\title{
Blue-enhanced thin-film photodiode for dual-screen $x$-ray imaging
}

Cite as: Appl. Phys. Lett. 95, 263505 (2009); https://doi.org/10.1063/1.3276288

Submitted: 03 November 2009 • Accepted: 01 December 2009 • Published Online: 31 December 2009

Y. Vygranenko, A. Sazonov, G. Heiler, et al.

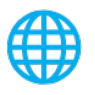

\section{ARTICLES YOU MAY BE INTERESTED IN}

Optimization of back reflector for high efficiency hydrogenated nanocrystalline silicon solar cells

Applied Physics Letters 95, 263501 (2009); https://doi.org/10.1063/1.3279143

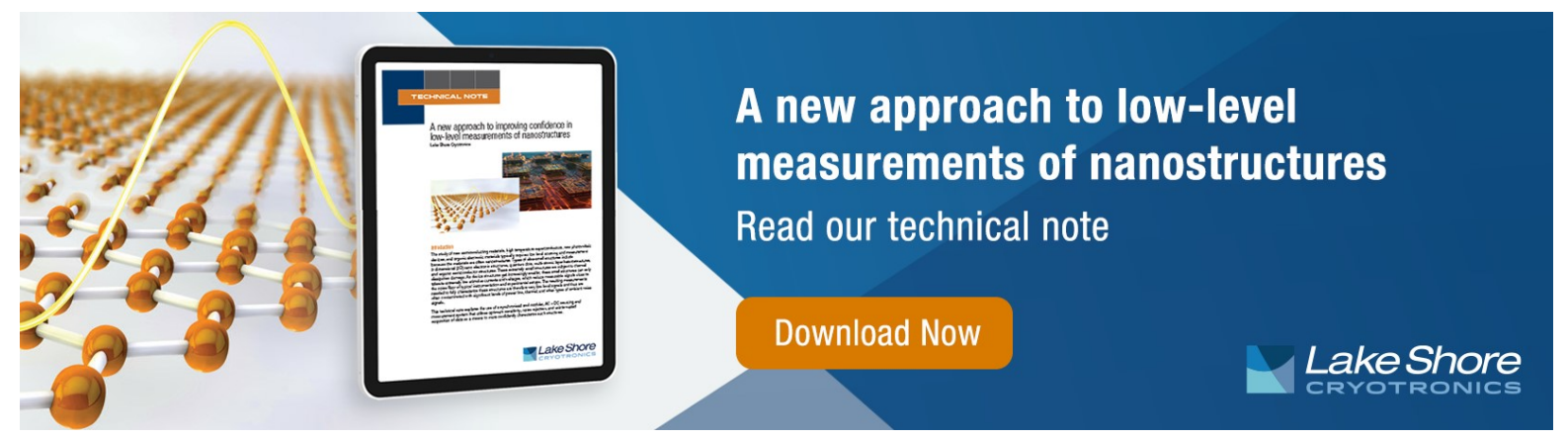




\title{
Blue-enhanced thin-film photodiode for dual-screen x-ray imaging
}

\author{
Y. Vygranenko, ${ }^{1, a)}$ A. Sazonov, ${ }^{2}$ G. Heiler, ${ }^{3}$ T. Tredwell, ${ }^{3}$ M. Vieira, ${ }^{1}$ and A. Nathan ${ }^{4}$ \\ ${ }^{1}$ Department of Electronics, Telecommunications and Computer Engineering, ISEL, \\ Lisbon 1949-014, Portugal \\ ${ }^{2}$ Electrical and Computer Engineering, University of Waterloo, Waterloo N2L 3G1, Canada \\ ${ }^{3}$ Carestream Health, Inc., Rochester, New York 14652-3487, USA \\ ${ }^{4}$ London Centre for Nanotechnology, University College London, London WC1H OAH, United Kingdom
}

(Received 3 November 2009; accepted 1 December 2009; published online 31 December 2009)

\begin{abstract}
This article reports on $a$-Si:H-based low-leakage blue-enhanced photodiodes for dual-screen $\mathrm{x}$-ray imaging detectors. Doped nanocrystalline silicon was incorporated in both the $n$ - and $p$-type regions to reduce absorption losses for light incoming from the top and bottom screens. The photodiode exhibits a dark current density of $900 \mathrm{pA} / \mathrm{cm}^{2}$ and an external quantum efficiency up to $90 \%$ at a reverse bias of $5 \mathrm{~V}$. In the case of illumination through the tailored $p$-layer, the quantum efficiency of $60 \%$ at a $400 \mathrm{~nm}$ wavelength is almost double that for the conventional $a-\mathrm{Si}: \mathrm{H} n-i-p$ photodiode. (C) 2009 American Institute of Physics. [doi:10.1063/1.3276288]
\end{abstract}

Flat-panel digital x-ray image sensors of the indirect conversion type comprise a phosphor screen that is optically coupled to a large-area hydrogenated amorphous silicon $(a-\mathrm{Si}: \mathrm{H})$ photodiode array, which converts light into electrical signal. ${ }^{1}$ Contrary to conventional high-resolution screen systems, where the $\mathrm{x}$-rays pass through the screen before impinging on the phosphor, commercial digital systems are configured in a less-favorable, front-screen orientation that yields lower image quality. ${ }^{2}$ An alternative device design is shown in Fig. 1(a). Here, the sensor array is disposed between the bottom and top phosphor screens providing more efficient optical coupling. The dual-screen configuration allows a design trade-off between spatial resolution and x-ray absorption efficiency by adjusting the thicknesses of the phosphor layers. Moreover, the pixels of the sensor array can be selectively coupled to the top and/or bottom screens, which are made of matched phosphor materials, thus extending the application for single-exposure, dual-energy subtraction imaging. ${ }^{3}$ Thallium-doped cesium iodide (CsI:Tl) is proposed as a phosphor material for the bottom screen because of its high scintillation efficiency and large-area processing capability. ${ }^{4}$ The one disadvantage is that CsI:Tl loses its scintillation properties at temperatures above $300{ }^{\circ} \mathrm{C}$. On the other hand, the thermal annealing at $150{ }^{\circ} \mathrm{C}$ may increase the light output. ${ }^{5,6}$ For successful device integration, the deposition of the semiconductor, insulator, and transparent conducting oxide films should be carried out at a moderate process temperature to prevent the degradation of the bottom phosphor. Low-temperature processes for $a$-Si: $\mathrm{H}$ thin-film transistors have been already developed. ${ }^{7,8}$ In this work, we report on a $150{ }^{\circ} \mathrm{C}$ blue-enhanced photodiode developed for dual screen $\mathrm{x}$-ray imaging.

Figure 1(b) shows a cross-sectional view of an $a$-Si:H-based heterojunction $p-p^{\prime}-\delta_{i}-i-n$ photodiode structure presented in this work. The structure is sensitive to light incident on the top and/or bottom $\mathrm{ZnO}: \mathrm{Al}$ electrodes. With the goal to reduce absorption losses, a doped hydrogenated nanocrystalline silicon (nc-Si:H) is incorporated in both $p$ and $n$-type regions. The doped nc-Si:H layer has advantages

${ }^{a)}$ Electronic mail: yvygranenko@deetc.isel.ipl.pt. over $a-\mathrm{Si}: \mathrm{H}$ or amorphous silicon carbide $(a-\mathrm{SiC}: \mathrm{H})$ with respect to higher conductivity and lower optical absorption in the visible range. ${ }^{9}$ However, the formation of a goodquality nc-Si:H/a-Si:H $p-i$ interface on the metal oxide surface is a technological issue associated with the nucleation layer, complex microstructure of the heterogeneous material, defects at grain boundaries, and voids. In our device, a double $p-\mathrm{nc}-\mathrm{Si}: \mathrm{H} / p^{\prime}-a-\mathrm{SiC}: \mathrm{H}$ structure with a thin $(\sim 4 \mathrm{~nm})$ buffer $\delta_{i}$-layer is implemented to improve the quality of the heterojunction interface. The optical bandgap of the $p$-type $a-\mathrm{SiC}: \mathrm{H}$ is evaluated to be $2.0 \mathrm{eV}$. The bandgap of an undoped $a-\mathrm{SiC}: \mathrm{H}$ for the $\delta_{i}$-layer is reduced to $1.9 \mathrm{eV}$ to minimize the band offsets of the heterojunction interface. The role of the $\delta_{i}$-layer in the $a-\mathrm{Si}: \mathrm{H} n-i-p$ photodiodes with $a$-SiC: $\mathrm{H} p$-layer has been discussed elsewhere. ${ }^{10}$

(a)

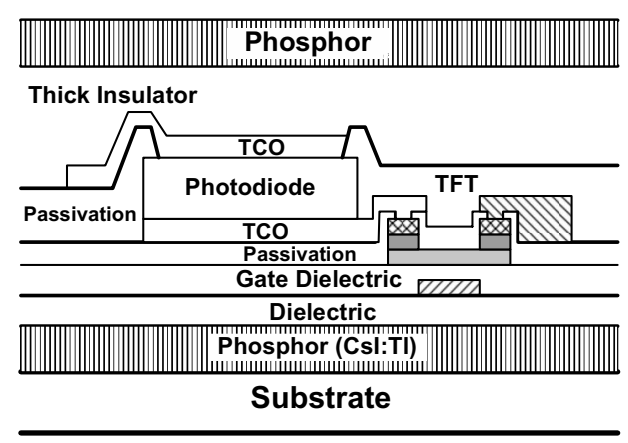

(b)

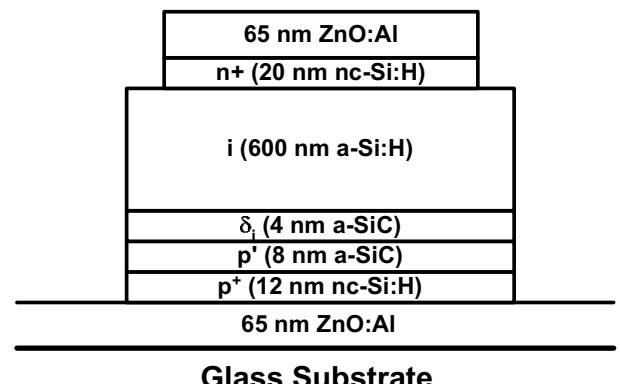

FIG. 1. Cross-sectional views of (a) detector pixel and (b) $p-p^{\prime}-\delta_{i}-i-n$ photodiode stack. 
TABLE I. Deposition conditions for the $p-p^{\prime}-\delta_{i}-i-n$ stack ("SCCM" denotes standard cubic centimeter per minute).

\begin{tabular}{lccccccc}
\hline \hline Layer & $\begin{array}{c}\mathrm{SiH}_{4} \\
(\mathrm{SCCM})\end{array}$ & $\begin{array}{c}\mathrm{H}_{2} \\
(\mathrm{SCCM})\end{array}$ & $\begin{array}{c}\mathrm{CH}_{4} \\
(\mathrm{SCCM})\end{array}$ & $\begin{array}{l}\mathrm{TMB}+\mathrm{H}_{2} \\
(\mathrm{SCCM})\end{array}$ & $\begin{array}{c}\mathrm{PH}_{3}+\mathrm{H}_{2} \\
(\mathrm{SCCM})\end{array}$ & $\begin{array}{c}\text { Pressure } \\
(\mathrm{mT} \text { Torr })\end{array}$ & $\begin{array}{r}\mathrm{rf} \mathrm{power} \\
\left(\mathrm{W} / \mathrm{cm}^{2}\right)\end{array}$ \\
\hline$p$ & 2 & 200 & $\ldots$ & 2 & $\ldots$ & 900 & 9 \\
$p^{\prime}$ & 10 & 25 & 14 & 15 & $\ldots$ & 600 & 18 \\
$\delta_{i}$ & 10 & 40 & 9 & $\ldots$ & $\ldots$ & 500 & 18 \\
$i$ & 15 & 45 & $\ldots$ & $\ldots$ & $\ldots$ & 600 & 27 \\
$n$ & 2 & 200 & $\ldots$ & $\ldots$ & 2 & 900 & 9 \\
\hline \hline
\end{tabular}

The top $i-n$ heterojunction interface is simply formed by the deposition of a thin $(\sim 20 \mathrm{~nm}) \mathrm{nc}-\mathrm{Si}: \mathrm{H}$ film with sufficient crystallinity on the amorphous silicon surface.

The semiconductor layers were deposited in one-pumpdown process using a $13.56 \mathrm{MHz}$ multichamber plasmaenhanced chemical vapor deposition system at $150{ }^{\circ} \mathrm{C}$. The trimethylboron $\left[\mathrm{B}\left(\mathrm{CH}_{3}\right)_{3}\right](\mathrm{TMB})$ and phosphine $\left(\mathrm{PH}_{3}\right)$, diluted in hydrogen to a concentration of $1 \%$, were used as the doping gases. The deposition conditions for each layer are shown in Table I. The process sequence included sputtering $\mathrm{ZnO}: \mathrm{Al}$ on a Corning 7059 glass substrate, followed by the deposition of the $p-i-n$ stack, sputtering and patterning of the top $\mathrm{ZnO}$ :Al layer. The $n$-layer was selectively etched to suppress the lateral leakage current. The area of the top $\mathrm{ZnO}: \mathrm{Al}$ electrodes ranges from $2 \times 2$ to $5 \times 5 \mathrm{~mm}^{2}$.

Figure 2 shows typical quasistatic current-voltage characteristics of the $p-p^{\prime}-\delta_{p}-i-n$ structure. In order to minimize the transient current induced by trapped charge in the $i$-layer, the sweep delay was set to $20 \mathrm{~s}$, and the bias voltage was varied at $25 \mathrm{mV}$ increments. The diode shows an exponential dependence of the forward current over five orders of magnitude in the biasing range of $0.2-0.6 \mathrm{~V}$. The diode ideality factor $(n)$ and the saturation current density $\left(J_{\mathrm{o}}\right)$ are determined to be 1.57 and $450 \mathrm{fA} / \mathrm{cm}^{2}$, respectively. These values are similar to that reported for the $a-\mathrm{Si}: \mathrm{H} p-i-n$ diodes with an optimized $i-p$ interface. ${ }^{11}$ The reverse dark current increases, albeit slowly, with increasing bias in the range up to $2 \mathrm{~V}$. Here, the current density of $13 \mathrm{pA} / \mathrm{cm}^{2}$ at $-1 \mathrm{~V}$ is comparable to that reported for state-of-the-art $a$-Si: $\mathrm{H}$ photodiodes. ${ }^{12}$ At higher reverse biases, when the $p^{\prime}-\delta_{i}-i$-layers are fully depleted and the depletion region expands into the nc-Si:H p-layer, the leakage current increases nearly exponentially, reaching a value of $900 \mathrm{pA} / \mathrm{cm}^{2}$ at $-5 \mathrm{~V}$.

Figures 3 shows the external quantum efficiency (EQE) spectra of the $p-p^{\prime}-\delta_{i}-i-n$ structure illuminated through the top and bottom contacts under different biasing conditions.

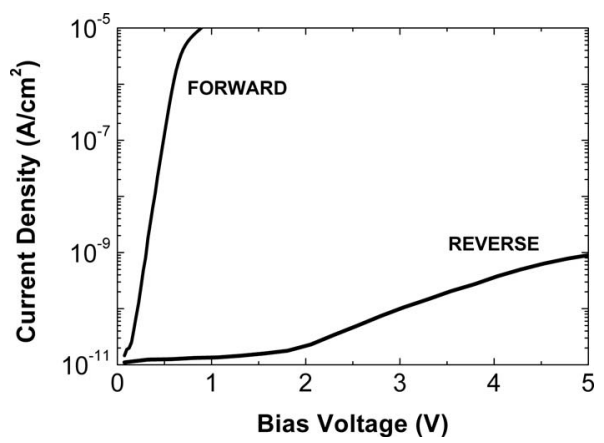

FIG. 2. Dark current-voltage characteristics of the $p-p^{\prime}-\delta_{i}-i-n$ stack.
The spectrum of a conventional $a-\mathrm{Si}: \mathrm{H} n-i-p$ photodiode with a $20 \mathrm{~nm}$ thick $p$-layer is also shown for comparison. Measurements were performed using a lock-in technique at a light modulation frequency of $36 \mathrm{~Hz}$.

Under illumination through the $p$-layer, the spectralresponse characteristics, measured at zero bias and a reverse bias of $5 \mathrm{~V}$, look similar. The EQE of the biased device reaches a peak value of $84 \%$ at a $520 \mathrm{~nm}$ wavelength and gradually decreases down to $63 \%$ at a $400 \mathrm{~nm}$ wavelength exceeding the respective value for the conventional $a-\mathrm{Si}: \mathrm{H}$ $n-i-p$ photodiode by factor of 1.9. Under short-circuit conditions, the EQE is slightly lower in the short- and longwavelength regions, which is typical for $a$-Si:H photodiodes with an optimized $i$ - $p$ interface and device-quality $i$-layer material. However, when the structure is illuminated through the $n$-layer, the spectral-response characteristics are strongly bias-dependent. The peak values are $51 \%$ and $90 \%$ at zero bias and reverse bias of $5 \mathrm{~V}$, respectively. The strong bias dependence of the EQE can be related to the recombination of photogenerated carriers in the $i$-layer and/or at the $n-i$ interface.

Figure 4 shows the EQE as a function of the reverse bias voltage measured at different wavelengths. At a $530 \mathrm{~nm}$ wavelength under illumination through the $n$-layer, the photocurrent increases by a factor of 2 at reverse biases ranging from 0 to $1.5 \mathrm{~V}$ and saturates when the $i$-layer becomes fully depleted. At a $400 \mathrm{~nm}$ wavelength, carrier generation is strongly nonuniform, and the EQE progressively changes by an order of magnitude over the measured voltage range, i.e., $\operatorname{EQE}(0 \mathrm{~V}) / \operatorname{EQE}(7 \mathrm{~V})=0.1$. The bias control of sensitivity enables decoupling of the light signal from the top and bottom screens, which can be used for detector calibration or multimode detection.

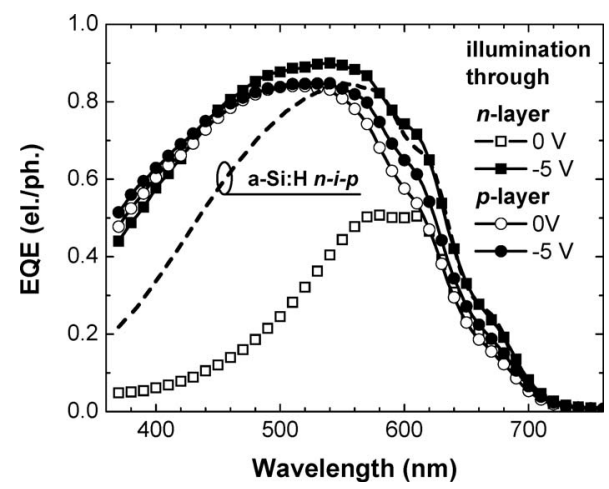

FIG. 3. EQE spectra of the $p-p^{\prime}-\delta_{i}-i-n$ stack illuminated through the $p$-layer (circles) and the $n$-layer (squares). Spectrum of the $a-\mathrm{Si}: \mathrm{H} n-i-p$ photodiode is also shown (dashed line) 


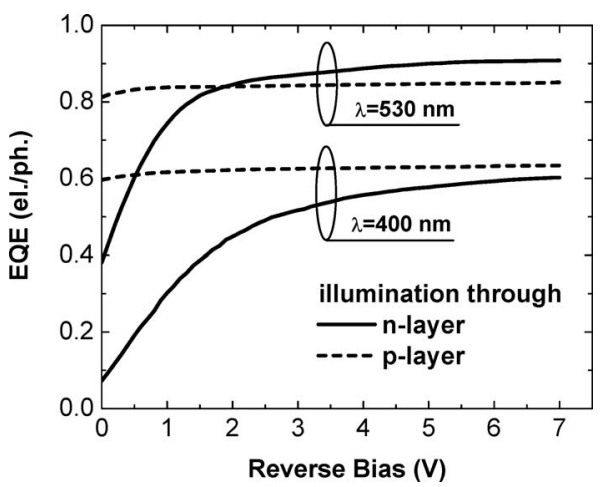

FIG. 4. Quantum efficiency as a function of reverse bias at 400 and $530 \mathrm{~nm}$ wavelengths.

In summary, we have fabricated and characterized $a$-Si:H-based $p-p^{\prime}-\delta_{i}-i-n$ photodiodes configured for dualscreen $\mathrm{x}$-ray imaging detectors. An enhanced sensitivity in the UV/blue range was achieved by incorporating doped nc$\mathrm{Si}: \mathrm{H}$ as a contact material. The recombination-induced leakage current was suppressed by implementing an $a-\mathrm{SiC}: \mathrm{H}$ $p^{\prime}-\delta_{i}$ buffer between the nanocrystalline $p$-layer and the $a$-Si:H $i$-layer.

${ }^{1}$ Technology and Applications of Amorphous Silicon, edited by R. A. Street (Springer, Berlin, 2000).

${ }^{2}$ Handbook of Medical Imaging, edited by J. Beutel, H. L. Kundel, and R. Van Metter (SPIE, Washington, DC, 2000).

${ }^{3}$ D. L. Ergun, C. A. Mistretta, D. E. Brown, R. T. Bystrianyk, W. K. Sze, F. Kelcz, and D. P. Naidich, Radiology 174, 243 (1990).

${ }^{4}$ B. K. Cha, J.-H. Shin, J. H. Bae, C. Lee, S. Chang, H. K. Kim, C. K. Kim, and G. Cho, Nucl. Instrum. Methods Phys. Res. A 604, 224 (2009).

${ }^{5}$ R.-Y. Zhu, IEEE Trans. Nucl. Sci. 44, 468 (1997).

${ }^{6}$ M. A. H. Chowdhury and D. C. Imrie, Nucl. Instrum. Methods Phys. Res. A 432, 138 (1999).

${ }^{7}$ A. Sazonov, A. Nathan, and D. Striakhilev, J. Non-Cryst. Solids 266, 1329 (2000).

${ }^{8}$ H. Gleskova, S. Wagner, V. Gasparik, and P. Kovac, J. Electrochem. Soc. 148, G370 (2001).

${ }^{9}$ H. Chen, M. H. Gullanar, and W. Z. Shen, J. Cryst. Growth 260, 91 (2004).

${ }^{10}$ P. Servati, Y. Vygranenko, and A. Nathan, J. Appl. Phys. 96, 7578 (2004).

${ }^{11}$ C. van Berkel, M. J. Powell, A. R. Franklin, and I. D. French, J. Appl. Phys. 73, 5264 (1993).

${ }^{12}$ R. A. Street, Appl. Phys. Lett. 57, 1334 (1990). 